\title{
The role of biogeochemical processes in the transformation of certain components in the Environmental geology
}

Artem Demenev M.Sc

Demenev A. The role of biogeochemical processes in the transformation

of certain components in the Environmental geology.

J Environ Geol. 2017;1(1):5-6.

$\mathrm{M}_{\mathrm{n}}$ icrobiological activity affects the habitat of microorganisms in three main ways (methods): by changing the components of the solid, liquid and gas phases of the soil; by changing in acid-base conditions of the environment; by changing in the oxidation-reduction conditions of the environment [using different compounds as the final electron acceptors in metabolic processes].

The characteristics of the physiology of microorganisms, their influence on minerals, organic substances, gases, and also their wide - spread occurrence in soils, give every reason to expect that they exert a considerable influence and physico-mechanical characteristics of soils. Analysis of literature data (111) and established features of the distribution of microorganisms make it possible to distinguish among them only certain groups and special cases, influences on the formation and change of soil properties. IN Bolotin and EM Sergeev note that the properties of soils depend on the composition of all its components in their correlation and interaction (1).

Geologically, the study of microbiological processes has been beginning with the 70s of the last century. In 1973 VV Radina published a paper of the role of the biotic component in the formation of soil properties and their stress state (12). LL Koff and LS Kozhevina also plays a significant role in changing the geological environment to microorganisms (13). Microorganisms can destroy the most important mineral components of rock, such as silicates and aluminosilicates (1). Subtractor of elements from minerals where there are microorganisms is two to three times higher than under the action of water. The features of the subtraction of elements are determined by the strength of the bonds of atoms in the structure of the crystal lattice, the type of microorganism and the conditions of decomposition. A more active influence on the soil is due to the ability of microbes to oxidize and reduction elements with variable valence, which are part of the crystalline lattice of minerals; the influence of metabolites $\left[\mathrm{H}_{2} \mathrm{SO}_{4}, \mathrm{HNO}_{3}\right.$, organic acids, alkalis, hydrogen sulphide, etc.]. The mineral can be completely destroyed, or [with selective removal of elements] transformed into another. IN Bolotina notes that the transformation of some minerals into others occurs when selective removal of individual elements from the crystal lattice or during the oxidation and reduction of elements that make up the crystal lattice (14). TN Nizharadze studied the role of microorganisms in the formation of gelling processes at St. Petersburg State University, it is noted that the spread of this process causes significant damage to the state of the environment, as a result of its impact are formed rocks of special composition, structure, and properties (15). NG Maksimovich and VT Khmurchik (7) note the need to study the behavior of microorganisms in the geological environment and their reactions to external influences. Which will allow us to evaluate the role of microbial processes in the transformation of engineering-geological conditions. The study of the influence of micro biota to the components of the geological environment, as well as on engineering and geological conditions, is conducted under the direction of RE Dashko. It is established that microbiological processes can significantly influence to the engineeringgeological characteristics of soil body (3-5). The role of microbial processes in the formation of certain conditions in engineering geological massifs has been estimated. This is illustrated by the example of different objects [the underground space of St. Petersburg, some hydroelectric power station in east Europe, the St. Petersburg-Kiev transport tunnel, etc.]. It is required to assess the changes in engineering-geological conditions in time under the influence of microbiological processes to ensure the safe operation of buildings and structures On the one hand, human activity violates the conditions of the course in the environment of many natural processes, including microbial ones. At the same time, there is often an increased in some undesirable microbiological processes in comparison with their rate in natural conditions. Examples of such situations are data on the participation of microorganisms in the processes of bio corrosion, the formation of acid aggressive mine waters, information about the possible role of microorganisms in the formation of quicksand, etc. On the other hand, microorganisms can help maintain the desired environmental parameters. Examples of this are "microbiological barriers" between the environment and the removal of matter from industrial landscapes (16).

However, using of biotechnology, it is possible to control the direction of microbiological processes with the stimulation of individual groups of microorganisms, under certain conditions, the engineering-geological parameters of soil body can be improved (17). The Microbiologically induced calcite precipitation (MICP) technology has been successfully used in the last decade, however, its wide-scale application is limited by the need to cultivate and inject specific bacterial strains. Therefore, the future of this technology largely depends on the possibility of stimulating aboriginal microorganisms $(17,18)$. Various factors influence the sedimentation of calcite in the ground; therefore, the MICP technology has a general principle of operation, however, the techniques for implementing the technology, the solutions, their quantity and time of soaking the soils differ markedly from one author to another. At the moment, the authors have patented a number of their developments. In this case, the treatment of soils by solutions and microorganisms can be carried out in several stages, which complicates the application of this technology in practice. The authors of (19) recognize the relative complexity of soil treatment using MICP technology, which involves introducing foreign microorganisms into the ground, compared to strengthening soils with Portland cement. However, MICP technology is less expensive and environmentally friendly. Researchers note (20) that it may be more effective to stimulate aboriginal microflora of soils to further precipitate calcite. Therefore, in order to improve this technology and adapt it to wide application it is extremely important to conduct fundamental research on the possibility of stimulating aboriginal microbiocenosis in order to improve soil properties.

Thus, in the conditions of engineering activity it is important to study the living component of soils - microorganisms - in connection with the exploration of the geological environment. A more detailed research of this problem will help to prevent possible adverse and hardly predictable consequences of activation of microbiological processes, from the engineering-geological point of view. However, up to date, given the valuable contribution of domestic and foreign researchers to the solution of this problem, the methodology for studying the features of the formation of physicomechanical properties, mineral composition and the state of dispersed soils in conditions of activation of native microbiocenosis has not been determined. According to the results of the research, practically no statistically processed data are given, often the main conclusions are based on a single case or object. However, statistical data processing is an extremely important position in studying the physical and mechanical properties of soils. It should be noted that the existing information on the microbiological transformation and destruction

Department of Geology, Perm State University, Russia

Correspondence: Artem Demenev, Geologist/Environmental Engineer/Scientist, Department of Geology, Perm State University, Russia. Telephone +7-963-8732465, e-mail demenevartem@gmail.com

Received: September 10, 2017, Accepted: September 17, 2017, Published: September 24, 2017

OPEN ACCESS

This open-access article is distributed under the terms of the Creative Commons Attribution Non-Commercial License (CC BY-NC) (http:// creativecommons.org/licenses/by-nc/4.0/), which permits reuse, distribution and reproduction of the article, provided that the original work is properly cited and the reuse is restricted to noncommercial purposes. For commercial reuse, contact reprints@pulsus.com 
of individual minerals, including the constituents of dispersed soils, raises many questions. Basically, studies are related to model experiments - the effects of strains and groups of microorganisms on individual minerals. A comprehensive approach based on a broad scientific foundation is needed in order to understand the picture as a whole and to solve applied problems. Also, researchers noted the fact that the issue of the possibility of stimulating native microorganisms to improve soil properties has not been sufficiently studied. Although this direction is very promising in demand and significant for a wide range of applied and scientific tasks.

In this paper I have given a review of my research area and it is just one of the problems in modern Environmental Geology. There are a lot of similar issues and problems in this area and it is extremely important that there is a base or a place for accumulating research in this area. In my opinion, the journal "Environmental Geology" can be a great place to share the experience and achievements of modern researchers in the field of Environmental Geology. Moreover, research in this area is extremely important and necessary for further stable economic development, solving applied and scientific problems, as well as preserving the environment.

\section{REFERENCES}

1. Bolotina IN, Sergeev EM. Microbiological research in engineering geology. Eng Geol 1987;5:3-17.

2. Bolotina IN, Bolatbekova KS. Microorganisms in the processes of gleization of clayey soils. Eng Geol 1985;3:32-38.

3. Dashko RE, Vlasov D Yu, Shidlovskaya AV. Geotechnics and underground microbiota. SPb: printing house. 2014:280.

4. Dashko RE, Engineering-geological analysis and assessment of watersaturated clay rocks as base structures. SPb: printing house. 2015:383.

5. Dashko RE, Aleksandrova O Yu, Kotyukov PV, et al. Features of engineering and geological conditions of St. Petersburg. Urban development and geotechnical construction. 2011;13:25-71.

6. Ivanov PV, Nikolaeva SK, Manucharova NA, et al. Change in the microaggregate composition of technogenic soils during activation of the functional microbial complex. Engg Geol 2014;5:50-55.
7. Maximovich NG, Hmurchik VT. Microbiological processes in soil dams. Engineering Survey 2013;9:46-51.

8. Heron G, Christensen TH. Impact of sediment-bound iron on redox buffering in a landfill leachate polluted aquifer (Vejen, Denmark). Environmental Science and Technology 1995;29:187-192.

9. Heron $\mathrm{G}$, Christensen TH, Tjell JC. Oxidation capacity of aquifer sediments. Environmental Science and Technology 1994;28:153-158.

10. Heron G, Crouzet C, Christensen TH, et al. Speciation of Fe (II) and Fe (III) in contaminated aquifer sediments using chemical extraction techniques. Environ Sci Technol 1994;28:1698-1705.

11. Kaiser JP, Bollag JM. Microbial activity in the terrestrial subsurface. Experientia 1990;46:797-806.

12. Radina VV. The role of microorganisms in the formation of soil properties and their stress state. Hydrotechnical Construction 1973;9:22-24

13. Coff GL, Kozhevina LS. The role of microorganisms in changing the geological environment. Eng Geol 1981;6:63-74.

14. Bolotina IN, Brilling IA, Evdokimova LA, et al. Theoretical bases of engineering geology. Physicochemical basis: under the general. 1985:288.

15. Nizharadze TN. Geoecological testing of rocks based on protein synthesis: dis. for the competition uch. degrees of doc. geol.-min. Sciences: 11.00.11. St. Petersburg. 1997:332.

16. Kuznetsov SI, Ivanov MV, Lyalikova NN. Introduction to geological microbiology. Moscow: Nauka. 1962:239.

17. Gomez M, Anderson C, Dejong J, et al. Stimulating in situ soil bacteria for bio-cementation of sands. Geo-Congress: Technical Papers 2014:1674-1682.

18. Weaver TJ, Burbank M, Lewis A, et al. Bio-induced calcite, iron, and manganese precipitation for geotechnical engineering applications. GeoFrontiers 2011:3975-3983.

19. Rong H, Qian CX, Wang RX. Cementation method based on microbebased cement. Science China Tech Sciences 2011;54:1722-1729.

20. Burbank MB, Weaver TJ, Green TL, et al. Precipitation of Ccalcite by indigenous microorganisms to strengthen liquefiable soils. Geomicrobiology Journal 2011;28:301-312. 